УДК 621.311.26:006.354

\title{
ОБЗОР СТРУКТУР ГИБРИДНЫХ МИКРОЭЛЕКТРОСТАНЦИЙ С ВОЗОБНОВЛЯЕМЫМИ ИСТОЧНИКАМИ ЭНЕРГИИ ДЛЯ ДЕЦЕНТРАЛИЗОВАННЫХ ПОТРЕБИТЕЛЕЙ
}

\section{Андрианова Людмила Прокопьевна д-р техн. наук, профессор Гузаиров Айнур Ильгизович Голубев Дэнис Михайлович \\ Уфимский государственный нефтяной технический университет}

Аннотация. В статье приведена обобщенная конфигурация гибридной микроэлектростанции с возобновляемыми источниками энергии (ВИЭ) для энергоснабжения децентрализованных потребителей, удаленных от центральной энергосистемы. Показаны принципы построения гибридных микроэлектростанций для снабжения микросети с источниками ВИЭ постоянного и переменного тока без накопителей, с накопителями, при совместной и отдельной работе с дизельной генераторной установкой.

Ключевые слова: возобновляемые источники энергии; коллективная система электроснабжения; микроэлектростанция, микрогрид, фотоэлектрический генератор, ветродвигатель, накопитель, дизель-генератор.

\section{OVERVIEW OF HYBRID MICROELECTRIC POWER PLANT STRUCTURES WITH RENEWABLE ENERGY SOURCES FOR DECENTRALIZED CONSUMERS}

\section{Andrianova Lyudmila Prokopyevna Guzairov Ainur Ilgizovich Golubev Denis Mikhailovich}

\begin{abstract}
The article presents a generalized configuration of a hybrid microelectric power station with renewable energy sources (RES) for the power supply of decentralized consumers, remote from the central power system. The principles of construction of hybrid microelectric power plants for supplying a micro
\end{abstract}


grid with sources of renewable energy of direct and alternating current without storage devices, with storage devices, when working together and separately with a diesel generator set are shown.

Key words: renewable energy sources; collective power supply system; microelectric power station, microgrid, photovoltaic generator, wind turbine, storage unit, diesel generator.

Системы электроснабжения для энергоснабжения децентрализованных потребителей в соответствии $\quad$ с подразделяются на две категории:

1) Индивидуальные системы электроснабжения для единичного потребителя;

2) Коллективные системы электроснабжения для широкого числа потребителей.

К коллективным системам электроснабжения относятся энергетические установки, снабжающие децентрализованных потребителей электрической энергией, выработанной микроэлектростанцией, использующей один или несколько энергетических ресурсов.

Коллективные системы электроснабжения включают в себя три подсистемы:

- подсистему производства электроэнергии (микроэлектростанцию);

- подсистему распределения электроэнергии для передачи этой электроэнергии отдельным потребителям (микросеть);

- подсистему потребления электроэнергии, включая домашнюю проводку и бытовое электронное оборудование отдельных пользователей.

Микроэлектростанция - это электростанция, которая вырабатывает менее 50 кВ·А посредством использования одного энергетического ресурса или гибридной системы.

Микросеть - это электрическая сеть, которая перераспределяет мощность менее 50 кВ·А и питается от микроэлектростанции.

Передача электроэнергии может осуществляться:

- на постоянном токе;

- на переменном токе с инвертором, являющимся частью генерирующей подсистемы;

- на постоянном и переменном токе; 
- с одним конечным пунктом доставки электроэнергии с постоянным или переменным током;

- с несколькими конечными пунктами доставки электроэнергии.

Структура коллективной системы электроснабжения (КСЭ) с ВИЭ определяется подсистемой производства электроэнергии, выбор которой зависит от категории надежности потребителей [1,2]. Классификация коллективных систем электроснабжения с ВИЭ приведена в таблице 1.

Таблица 1

Классификация КСЭ в зависимости от типа генератора [2]

\begin{tabular}{|c|c|}
\hline Тип генератора & Обозначение ИСЭ \\
\hline $\begin{array}{l}\text { Только на основе ВИЭ, гибридная или нет, } \\
\text { без накопителя электроэнергии }\end{array}$ & $\mathrm{T}_{1} \mathrm{C}$ \\
\hline $\begin{array}{l}\text { Только на основе ВИЭ, гибридная или нет, } \\
\text { с накопителем электроэнергии }\end{array}$ & $\mathbf{T} \mathbf{2} \mathbf{C}$ \\
\hline $\begin{array}{l}\text { На основе ВИЭ, гибридная или нет + дизель-генератор, } \\
\text { без накопителя электроэнергии }\end{array}$ & T $3 \mathbf{C}$ \\
\hline $\begin{array}{l}\text { На основе ВИЭ, гибридная или нет + дизель-генератор, с } \\
\text { накопителем электроэнергии }\end{array}$ & $\mathrm{T}_{4} \mathrm{C}$ \\
\hline Только дизель-генератор без накопителя ЭЭ & T 5 C \\
\hline Только дизель-генератор с накопителем ЭЭ & $\mathrm{T}_{6} \mathrm{C}$ \\
\hline
\end{tabular}

КСЭ типа T1C: «Производство только с помощью ВИЭ без накопителя электроэнергии» является системой с низкой надежностью, т.е. неэффективной и ее структура не приводится в данной статье [2].

КСЭ типа Т2С: «Микроэлектростанция на основе ВИЭ, снабжающая микросеть», представлена на рис. 1. 


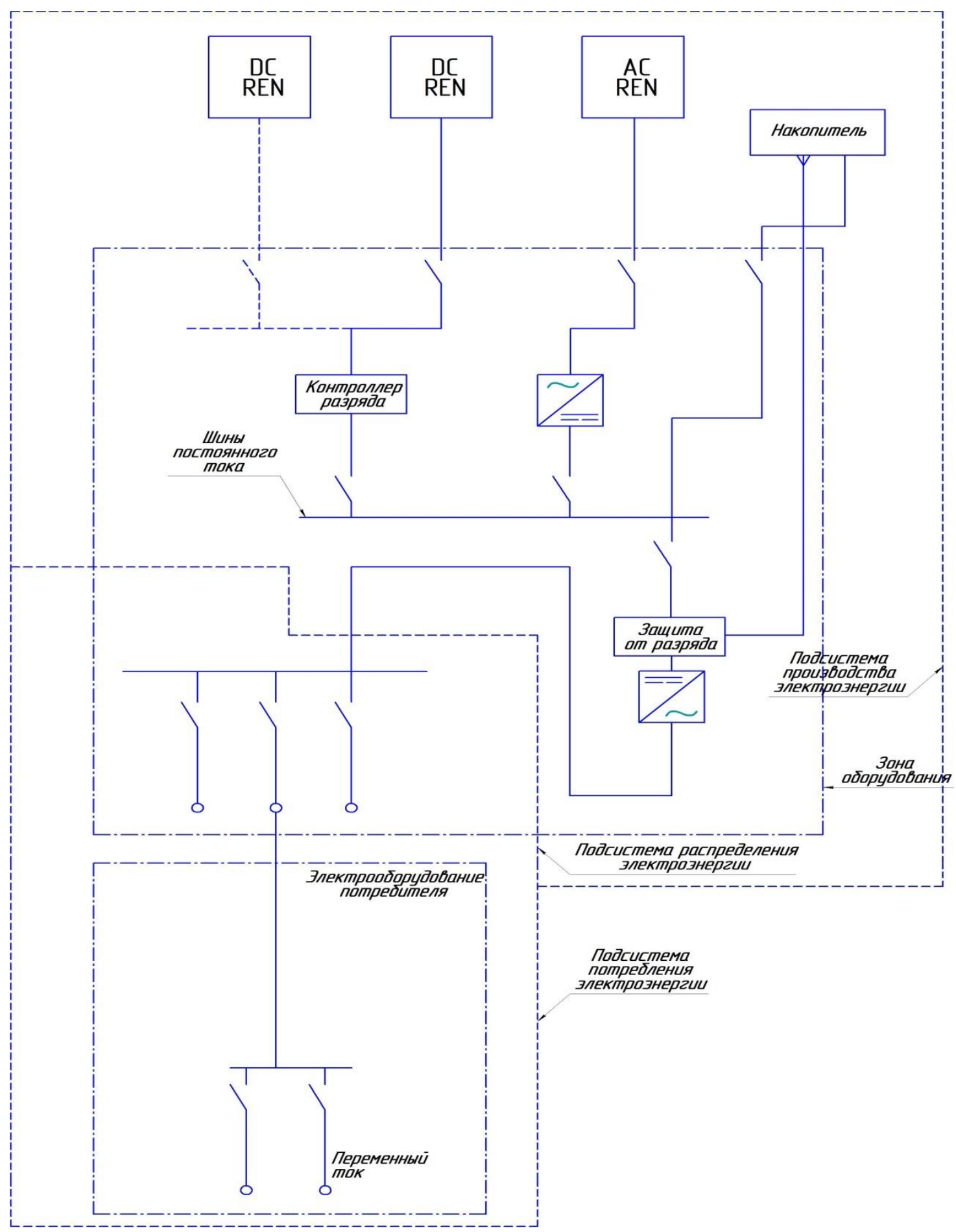

Рис. 1. Система типа Т2С- микроэлектростанция с ВИЭ и накопителями электроэнергии для снабжения микросети

КСЭ типа Т2 2 состоит из микроэлектростанции на основе ВИЭ с накопителями электроэнергии, которая может снабжать микросеть 
потребителей как в малонаселенной, имеющей несколько отдельно стоящих домов, так и в густонаселенной местности с группой домов или целого села.

Подсистема производства электроэнергии состоит из фотоэлектрического генератора и (или) ветродвигателя, распределительных щитов, обеспечивающих распределение электроэнергии по сети, и преобразователей напряжения для обеспечения стандартного значения выходного напряжения, обычно $230 \mathrm{~B}$.

Подсистема распределения электроэнергии состоит из линий электропередачи, подсоединенных к распределительным щитам подсистемы производства электроэнергии, воздушных линий или подземных кабелей и концевых распределительных коробок, расположенных в пунктах подключения потребителей электроэнергии, и образует радиальную структуру.

Подсистема потребления начинается от распределительных терминалов в пунктах подключения потребителей электроэнергии и содержит установки и оборудование потребителей электроэнергии, работающие исключительно на постоянном токе.

Общая структура системы типа $\mathbf{T} \mathbf{2} \mathbf{C}$ приведена на рис.2.

КСЭ типа Т3С: «Микроэлектростанция на основе источников разных типов (ВИЭ и дизель) без накопителя, снабжающая микросеть» имеет две модификации, указанные в таблице 2 [2].

Таблица 2

Возможные варианты КСЭ типа Т3С

\begin{tabular}{|c|l|c|}
\hline Тип & \multicolumn{1}{|c|}{ Источник ВИЭ } & Приемник \\
\hline $\mathrm{T}_{3} \mathrm{C}-\mathrm{a}$ & $\begin{array}{l}\text { Постоянный ток, например: } \\
\text { фотоэлектрический модуль } \\
\text { (РV-модуль) }\end{array}$ & Переменный ток \\
\hline $\mathrm{T}_{3} \mathrm{C}-\mathrm{b}$ & $\begin{array}{l}\text { Переменный ток, например: } \\
\text { ветродвигатель }\end{array}$ & Переменный ток \\
\hline
\end{tabular}




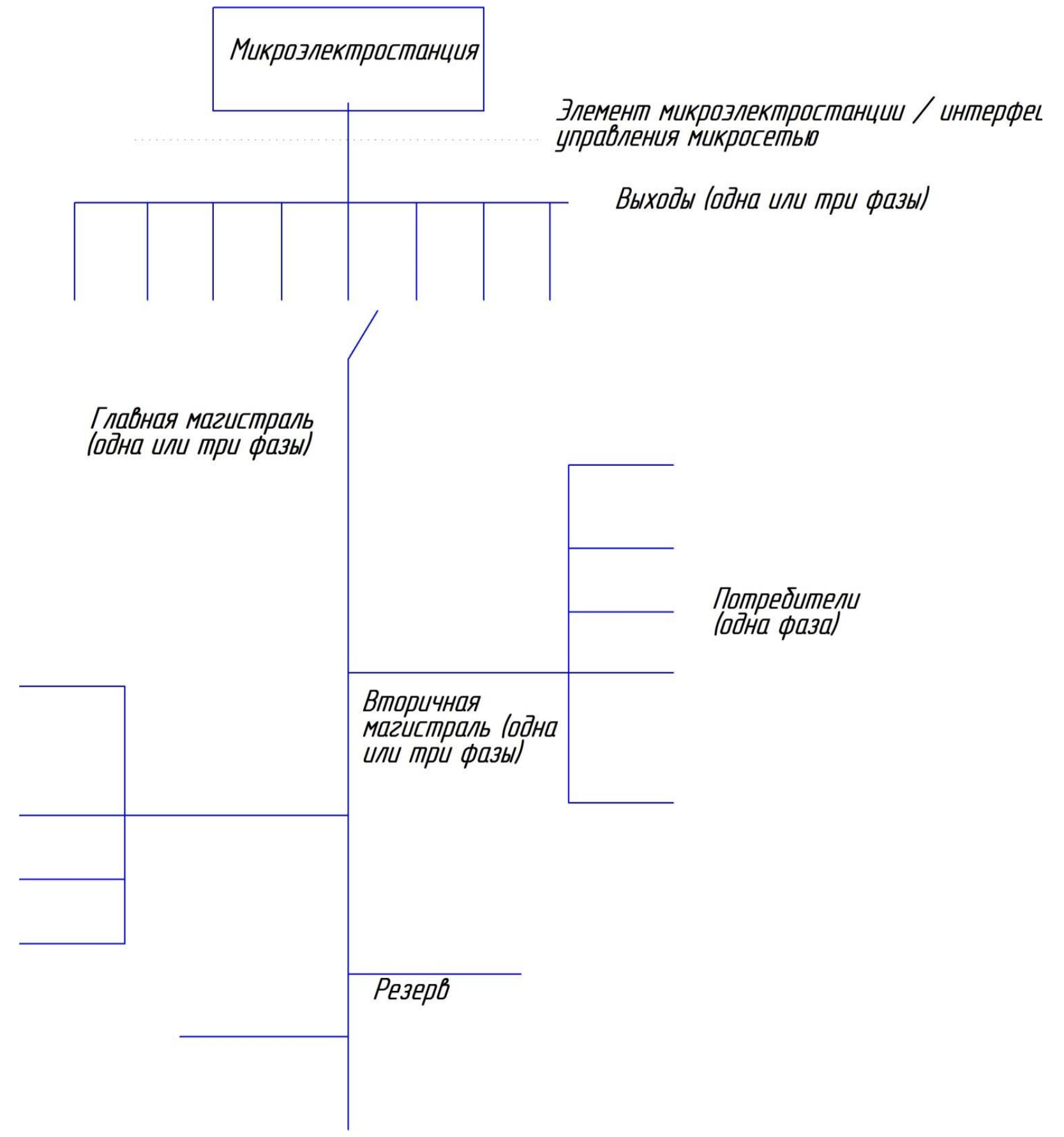

Рис. 2. Обобщенная структура микроэлектростанции для снабжения микросети

Функциональные схемы модификаций коллективной системы электроснабжения типа ТЗС представлены на рис. 3 и рис. 4. 


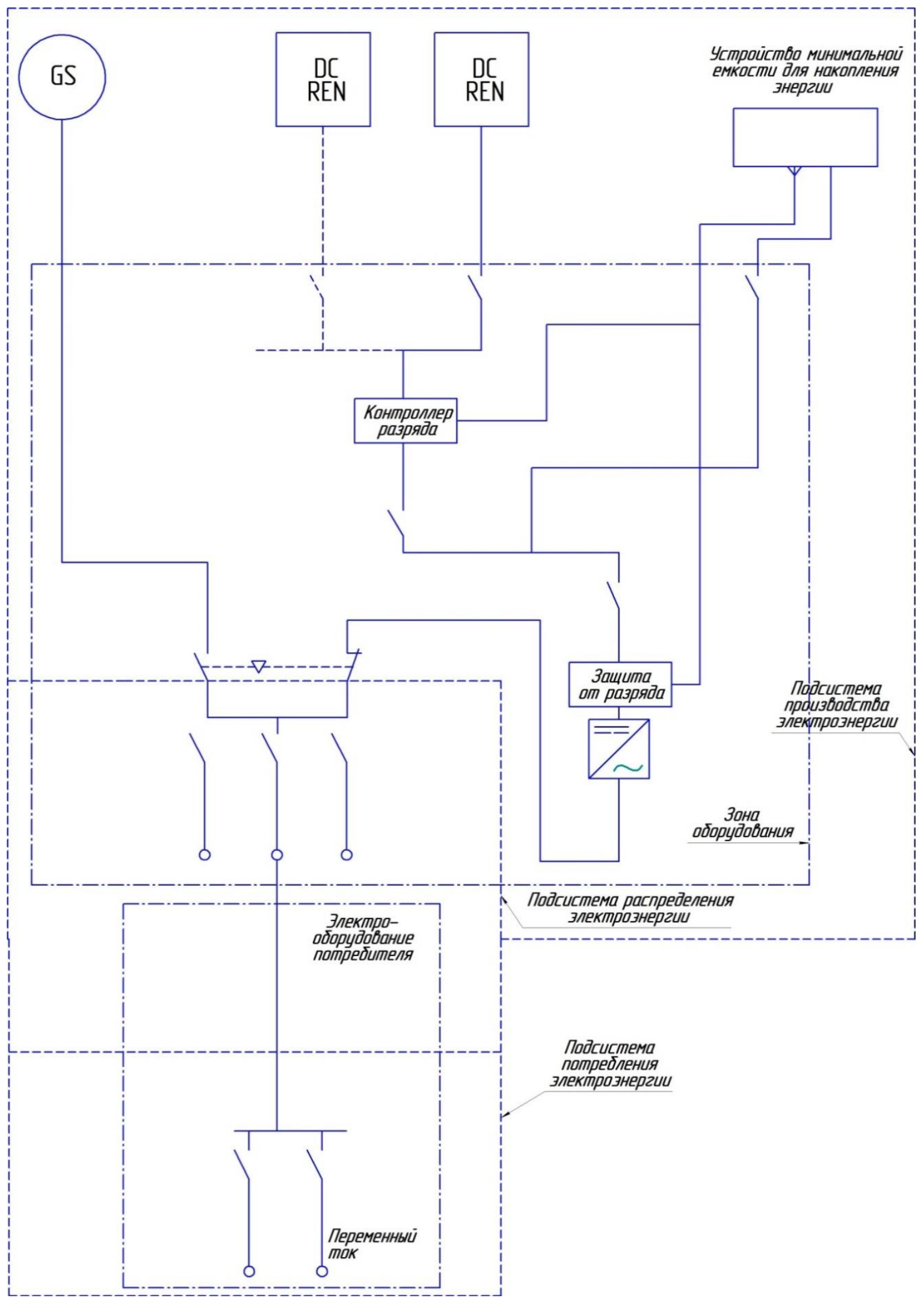

Рис. 3. Система типа Т3С-а - гибридная микроэлектростанция с источником постоянного тока без накопителя (PV-модуль и дизель) 


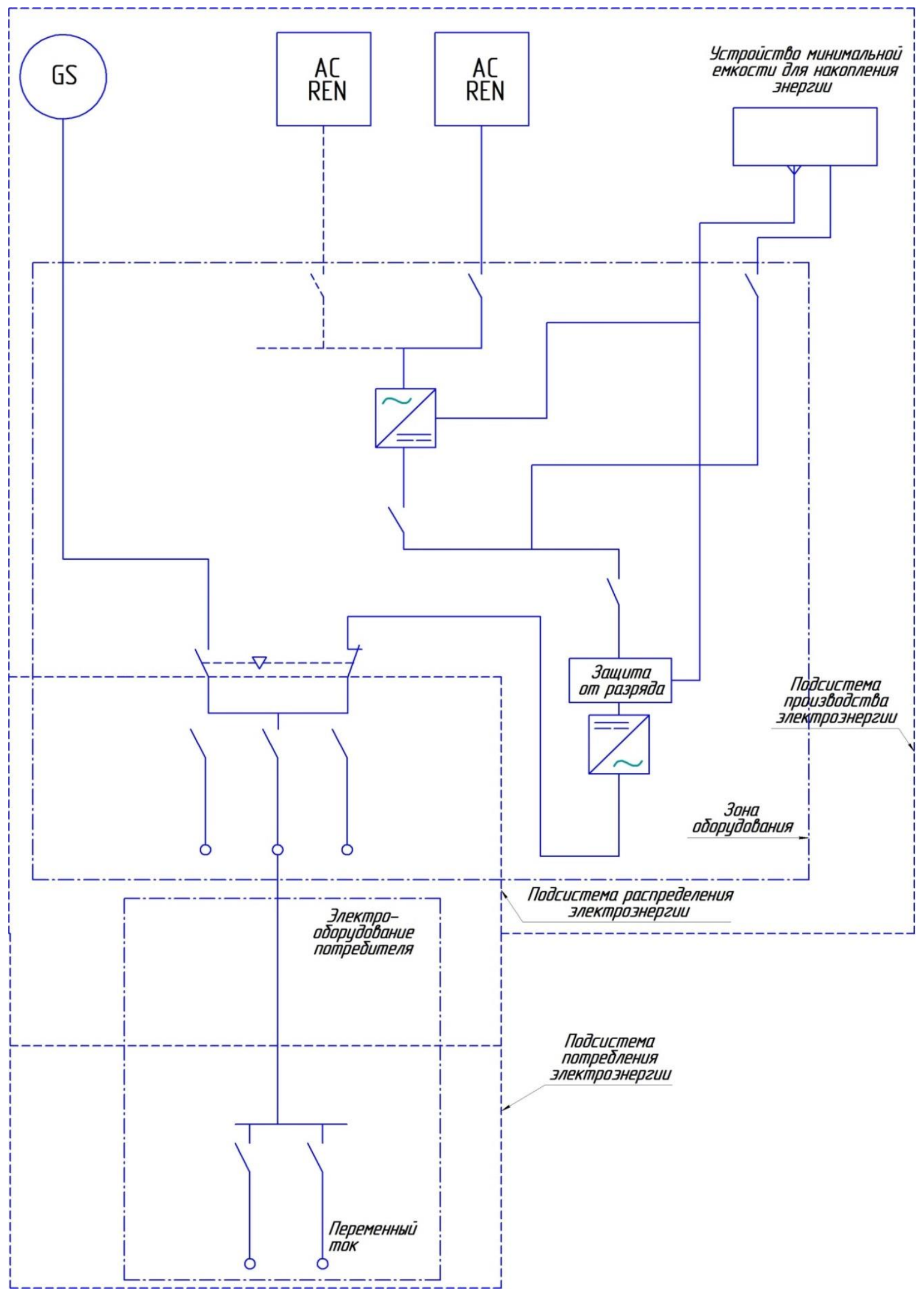

Рис. 4. Система типа Т3C-b - гибридная микроэлектростанция с источником переменного тока без накопителя (ветродвигатель и дизель) 
КСЭ типа Т3С включают дизельную и работающую на ВИЭ микроэлектростанции, синхронно связанные с системой [2].

Подсистема производства электроэнергии включает в себя буферную аккумуляторную батарею, предназначенную для установления необходимого напряжения на входе инвертора с целью исключения провалов напряжения в энергосети в моменты времени, когда генераторная установка выходит на заданный режим.

Эти системы применяют для выработки напряжения переменного тока. Все источники переменного тока, непосредственно связанные между собой, должны быть синхронизированы перед включением.

Подсистемы распределения и потребления электроэнергии имеют структуру, аналогичную структуре системы типа $\mathbf{T}_{2} \mathbf{C}$.

КСЭ типа T4С: «Гибридная микроэлектростанция с источниками разных типов (ВИЭ и дизель) с накопителем, снабжающая микросеть» имеет две модификации, указанные в таблице 3 [2].

Таблица 3

Возможные варианты схем КСЭ типа Т4C

\begin{tabular}{|c|c|c|}
\hline Тип & Источник ВИЭ & Приемник \\
\hline $\mathrm{T}_{4} \mathrm{C}-\mathrm{a}$ & Постоянный ток & Переменный ток \\
\hline $\mathrm{T} 4 \mathrm{C}-\mathrm{b}$ & Переменный ток & Переменный ток \\
\hline
\end{tabular}

Функциональные схемы модификаций КСЭ типа $\mathbf{T 4} \mathbf{C}$ представлены на рис. 5 и рис. 6.

Системы типа $\mathrm{T}_{4} \mathrm{C}$, представленные на рис. 5 и рис. 6, состоят из гибридной микроэлектростанции (ВИЭ и дизель) с накопителем электроэнергии и обеспечивают электроэнергией посредством микросети потребителей близлежащих сельских населенных пунктов. Эти системы содержат резервный генератор, который обеспечивает заряд аккумуляторных батарей. 


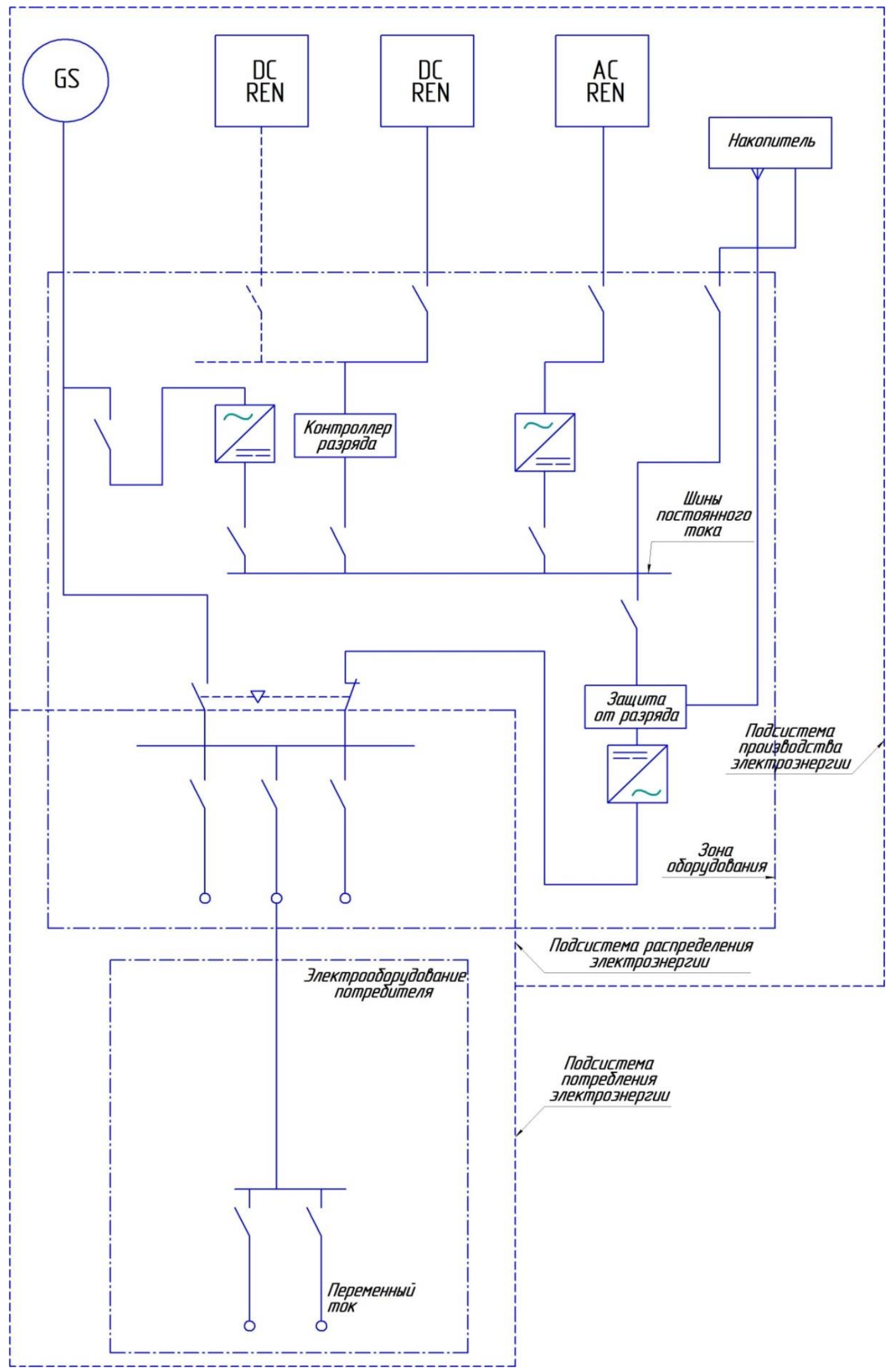

Рис. 5. Система типа T4C-a - гибридная микроэлектростанция с источниками разных типов с накопителем (ВИЭ и дизель) 


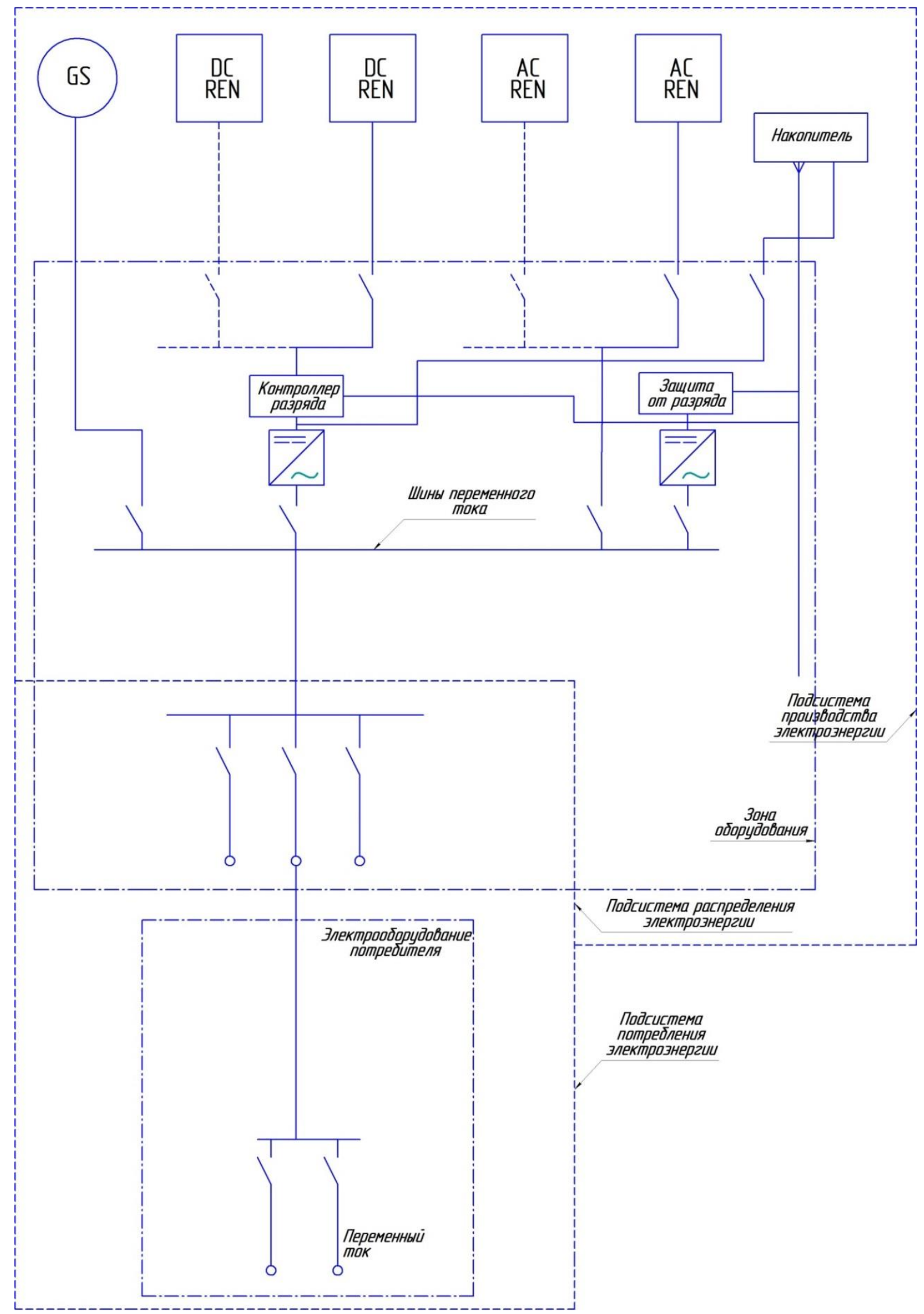

Рис. 6. Система типа T4C-b - гибридная микроэлектростанция с источниками разных типов с накопителем (ВИЭ и дизель) 
«Наличие резервного генератора GS в КСЭ типов $\mathbf{T 4 C - a , ~ T 4 C - b ~}$ позволяет также обеспечить бесперебойность поставки электроэнергии, что крайне важно, когда необходимо непрерывное электроснабжение (например, для медицинских диспансеров и холодильных камер хранения для вакцинных препаратов, школ, обеспечения хозяйственной и ремесленной деятельности и хозяйственно-питьевого водоснабжения)» [2]. От мощности резервного генератора микроэлектростанции будет зависеть количество потребителей электроэнергии и уровень предоставляемых услуг по электроснабжению.

При бытовом применении электроэнергии нет необходимости в подключении резервного генератора. Его наличие определяется требуемым качеством электроснабжения.

Подсистемы распределения и потребления электроэнергии имеют структуру, аналогичную структуре системы типа $\mathrm{T}_{2} \mathrm{C}$.

КСЭ типа T5C: «Микроэлектростанция на основе дизеля, снабжающая микросеть», представленная на рис. 7, состоит из дизельной микроэлектростанции, снабжающей микросеть. Единственным источником энергии является дизель-генератор. Как правило, установка работает в течение установленных интервалов времени [2].

Подсистемы распределения и потребления электроэнергии КСЭ типа T5C имеют структуру, аналогичную структуре системы типа $\mathbf{T 4 C}$.

КСЭ типа Т6С: «Микроэлектростанция на основе дизеля с накопителем, снабжающая микросеть», представленная на рис. 8, состоит из дизельной микроэлекгростанции GS c накопителем электроэнергии, снабжающей микросеть. Единственным источником энергии является дизель-генератор, снабжающий сеть и одновременно заряжающий аккумуляторную батарею [2]. 


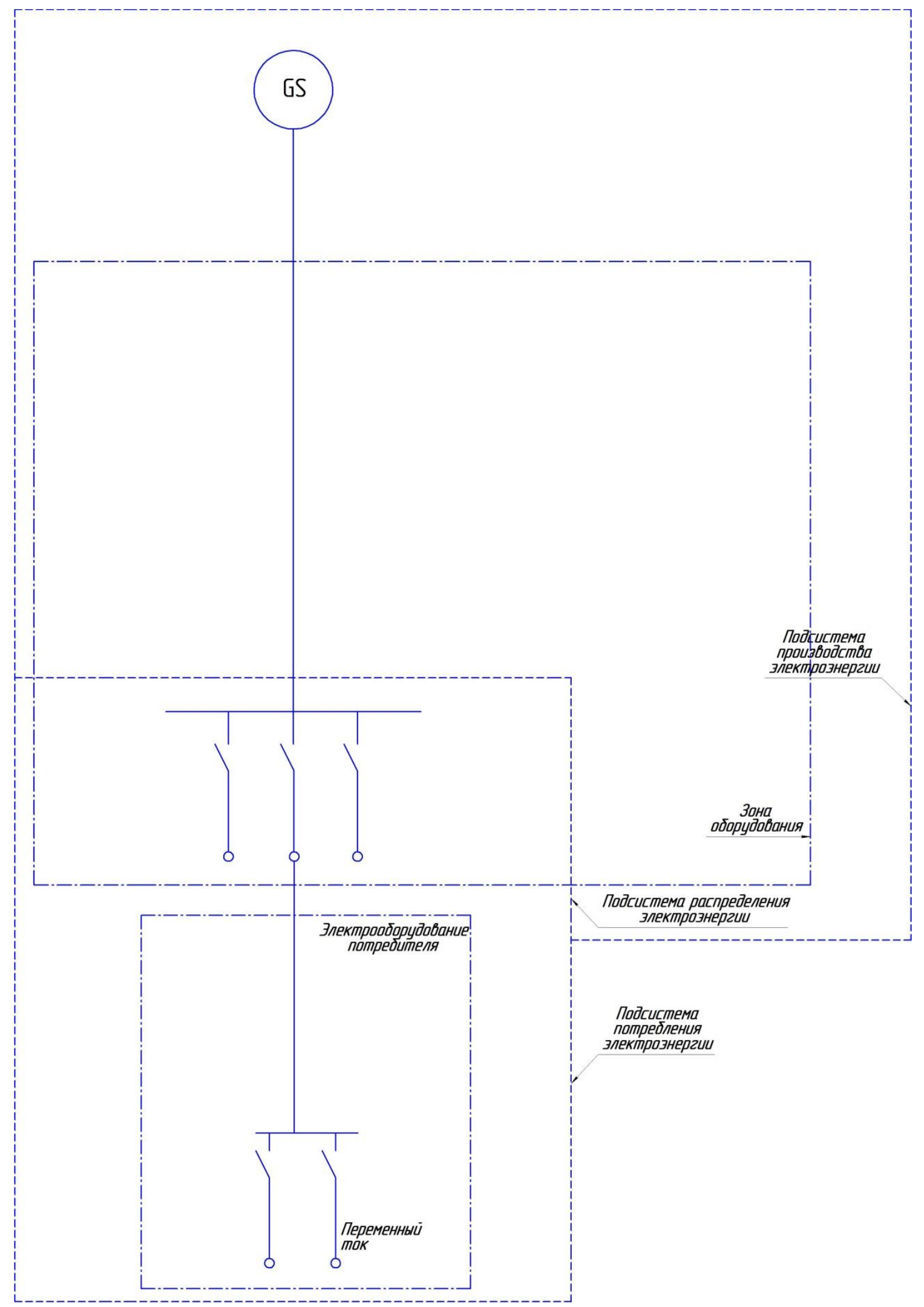

Рис. 7. Система типа T5C - микроэлектростанция на основе дизеля GS без накопителя [2] 


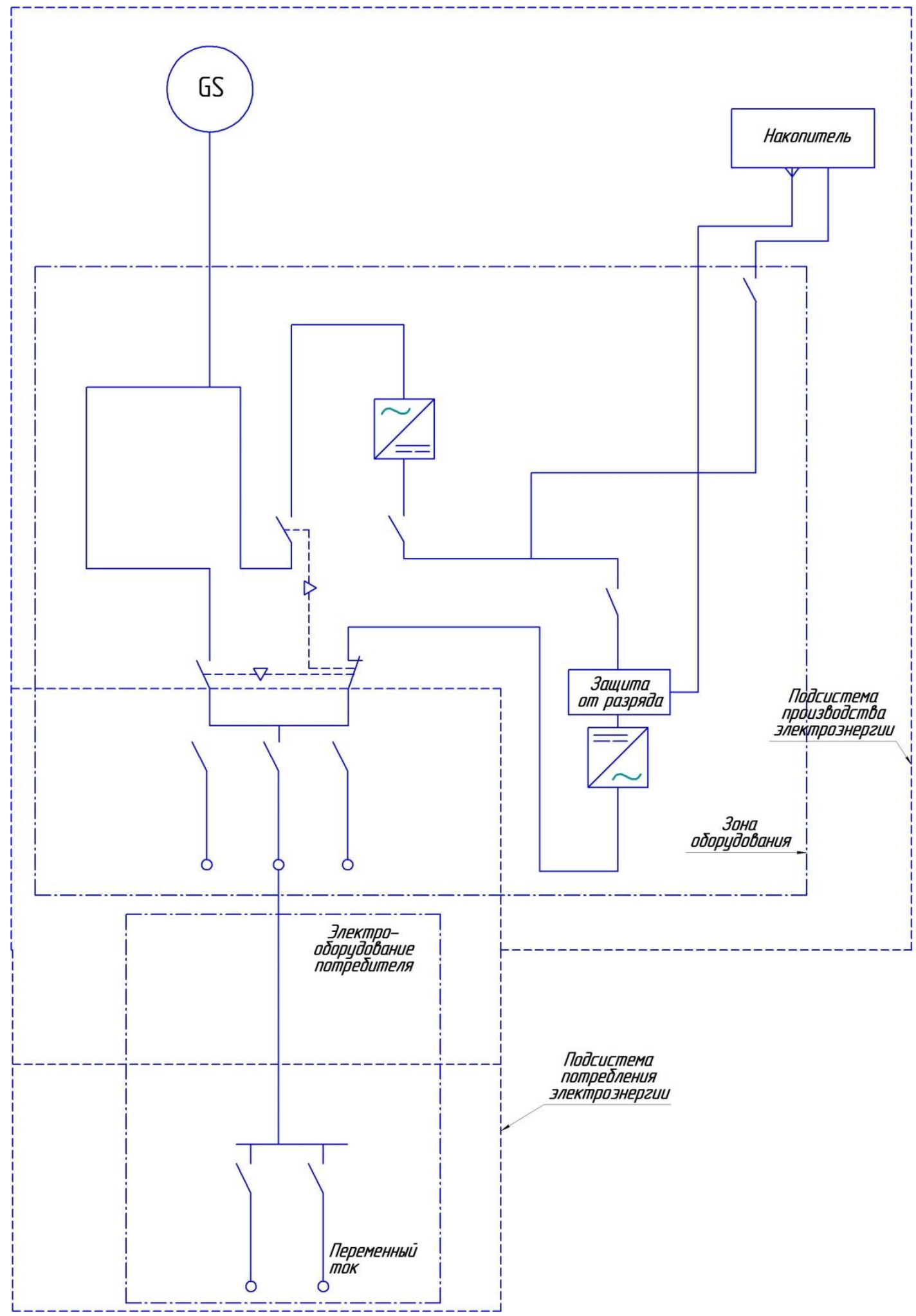

\section{Рис. 8. Система типа T6C - микроэлектростанция на основе дизеля GS с накопителем [2]}


Генераторная установка GS работает в течение запланированного интервала времени. При отсутствии функционирования генераторной установки, бесперебойность электроснабжения обеспечивается посредством аккумуляторной батареи.

Подсистемы распределения и потребления электроэнергии КСЭ типа T6C имеют структуру, аналогичную структуре системы типа $\mathbf{T}_{2} \mathbf{C}$.

Заключение. Представленные функциональные схемы микроэлектростанций могут быть использованы при разработке децентрализованных коллективных систем электроснабжения с возобновляемыми источниками энергии для значительного числа потребителей. При конкретном проектировании определяют количественные показатели энергопотребления, показатели качества электрической энергии, размеры различных частей системы: генераторов, накопителей, выключателей, устройств защиты.

\section{Список литературы}

1. ГОСТ Р 56124.1-2014 Возобновляемая энергетика. Гибридные электростанции на основе возобновляемых источников энергии, предназначенные для сельской электрификации. Рекомендации. Часть 1. Общее введение для сельской электрификации. - М.: Стандартинформ, 2016. - 13 с.

2. ГОСТ Р 56124.2-2014 Возобновляемая энергетика. Гибридные электростанции на основе возобновляемых источников энергии, предназначенные для сельской электрификации. Рекомендации. Часть 2. Из требований по классификации систем электроснабжения. - М.: Стандартинформ, 2016. - 52 с.

(С) Л.П. Андрианова, А.И. Гузаиров, Д.М. Голубев, 2021 